Research Journal of Applied Sciences 5 (6): 471-479, 2010

ISSN: $1815-932 \mathrm{X}$

(C) Medwell Journals, 2010

\title{
Empowering Young Adult Learners, Engaging Critical Thinking: Learner's Perspective
}

\author{
M.M. Raihanah and S.S. Mary-Ann \\ School of Language Studies and Linguistics, Faculty of Social Sciences and Humanities, \\ National University of Malaysia (UKM), 43600 Bangi, Selangor, Malaysia
}

\begin{abstract}
A critical mind is an empowering tool that allows the individual opportunity to participate in life as an active agent of change. In young adult learners, critical thinking is an evolving concept that requires careful consideration and the task of assisting this development rests among others in the hands of the education practitioners. What engages these groups of learners? What themes are of interest to them? What mode of learning interests them? The answers to these questions will be the enabling factor in engaging the mind and interests of these young adult. This study presents the findings of two case studies of young adult learners conducted at two institutions of higher learning in Selangor. Using both questionnaires and sample activities, the findings suggest that young adult learners generally are motivated to conduct critical thinking irrespective of the learning environment, albeit they require the appropriate stimulus including relevant choices of resources and methodology.
\end{abstract}

Key words: Critical thinking, young adult learners, self interest, self response, self perception, resources

\section{INTRODUCTION}

This study begins on the premise that a critical mind is an empowering tool that allows the individual the opportunity to participate in life as an active agent of change. The individual in this case is the young adult learner of tertiary education and the issue of empowerment revolves around the teaching and learning environment that equips each individual with the necessary tool to create a greater sense of awareness of how he/she can evolve as a young adult. However, in order to reach this desired outcome of producing empowered learners, teachers are in need of relevant information that can facilitate a more conducive teaching-learning environment. This is akin to what Ramsey and Fitzgibbons (Wohlfarth et al., 2008) describe as the shift from a purely imposing teaching methodology in which the teacher appears to be doing something to students to a more interdependent learning approach in which the teacher is merely being with students (Cleary, 1995).

The positionality in this study is that as educators, we need to be more aware of the crucial connection between the type of learners entering the class, i.e., what we term as the entry norm and the skills and knowledge these learners develop in the course of the lesson in the class room i.e., the learning outcome. This is because the knowledge of the students background, values, attitudes and assumptions (Locke, 1992) is indeed a vital pre-requisite towards engaging an empowered and critical mindsets. It is only with the said knowledge can educators begin to participate in a true learner centered approach which as Weimer (2002) (Being learner-centered is not about cowering in the competitive academic marketplace. It is not about kowtowing to students demands for easy options and is not about an ethnically irresponsible diminution of academic standards in an attempt to placate 'shoppers' who may opt to purchase educational products elsewhere) describes, Being learner-centered is not about cowering in the competitive academic marketplace. It is not about kowtowing to students demands for easy options and is not about an ethnically irresponsible diminution of academic standards in an attempt to placate shoppers who may opt to purchase educational products elsewhere) defines it is about creating climates in classes and on campus that advance learning outcomes. It is an orientation that advocates for more not less, learning. It is about offering a better product. This research sets out to begin the discussion on learner centered approach through an informed awareness of the types of students we receive at the first year undergraduate level in two institutions in Malaysia. The case studies aim to attain relevant and crucial information about the students in order to gain an insight into the learners perspective on the topic of empowerment and critical mind. Developing critical mindedness in young adult learners require among others, a more extensive recognition of learner needs. What engages these groups of learners? What themes are of interest to them? How do they relate to the different

Corresponding Author: Raihanah Mohd Mydin, School of Language Studies and Linguistics, Faculty of Social Sciences and Humanities, National University of Malaysia (UKM), 43600 Bangi, Selangor, Malaysia 
issues discussed in class? The answer to these questions will allow educators the necessary knowledge to answer the question How can I improve my students learning? (Weimer, 2002) and as well as assist learners to rethink what their role in the learning environment is in order to transform them from passive to active learners who think about ideas rather than about grades (Mezeske, 2004). In addition, the answer to the above mentioned questions will also assist the educators to identify pertinent topics and themes that will engage the mind and interests of these young adult learners.

The engaged mind construct as used in this study implies a sense of awareness on the part of the learner on the different values, perceptions and attitudes that colours his/her approach to learning; a mind which claim [s] responsibility for his own intellectual growth (ibid). Previous researches conducted on learner engagement suggest the need for a greater sense of awareness of the diversity of students entering the tertiary education annually (Vethamani and Keong, 2008; Too, 2006). This study presents the findings of two case studies of young adult learners conducted at two institutions of higher learning-a public and a private in Selangor. Using both questionnaires and sample activities, the research attempts to solicit feedback from these young adult learners in order to identify topics, themes and issues that may stimulate their interests and engage their mind.

Position of critical thinking in education: Young adult learners of today deal with many contemporary yet vivid concepts as well as ideas that dictate their learning process. In this way, it is useful to comprehend of certain standards, strategies and instructional methods that should be integrated in order to produce life-long learners (Cowley et al., 2006). Hence, in order to do so critical thinking skills become imperative to these young adult learners learning environment. Critical thinking employs intellectual approaches and competence which are used as conceptual tools in the process of making justifiable decisions about beliefs and points of view both within and outside of the classroom. Hence, critical thinking can be justified as a set of conceptual tools with associated intellectual skills and strategies useful for making reasonable decisions about what to do or believe (Rudinow and Barry, 2008).

Rhetorically speaking, how is critical thinking skills integrated into young adult learners in their confined classroom and what roles do educators play to this end? Firstly, a learner-centered teaching approach has to be constructed in order to facilitate critical thinking. In fact, as learner-centered theorists suggest, this approach requires a shift in mindset both for the educators and the learners. Unlike the traditional teacher centered approach which celebrates the knowledge and skills of the teacher, the learner centered one champions for a shift of responsibility to the students so that they can understand their learning strengths and weaknesses and feel self-directed in their knowledge quest Wohlfarth et al. (2008). This contemporary paradigm shift requires students to become critically aware of their own perceptions, values, beliefs, attitudes and backgrounds towards their learning process hence gearing these young learners to adopt critical thinking as second nature.

Conversely, assimilating critical thinking into the contemporary learning process of young adult learners may perhaps be a challenging task. One of the reasons being students learn from experience to become passive learners. As Mezeske (2004) discusses, young learners have developed a sense of the teachers action and answers being constantly right as well as to achieve grades that are of the teacher's benchmark instead of their own. Moreover as Wohlfarth et al. (2008) asserts, these students have developed an adaptability as unquestioning receivers of knowledge form an expert.

Hence, the task at hand for educators is to create the right learning environment to develop an empowered group of students who can begin to take responsibility of their learning (Mezeske, 2004). This outcome is achievable when educators take into consideration what drives and empowers young adult learners in the learning environment.

However, in addition to an engaged and critical mind, the students also need a voice in order to be an active participant of the learning process. Having a voice denotes the capacities for creativity, interpretation, self-profession and self-projection (Batchelor, 2008). Seen in another way, voice to take up Barnett and di Napolli (2008) statement can be defined as the projection of identity into the world or as an exercise of a learner's agency. In a nutshell, a student who has a voice in the learning space is equipped with the tool to shape his/her own paradigms of studenthood (Batchelor, 2008). In many ways, the ability for students to voice their thoughts about a topic be it through assignments or during class discussion is an indication of the use of his/her learner agency in the teaching and learning environment. However, the responsibility to nurture the voice in the students lies both in the individual learner as well as in the educator. As previous studies on this highlight educators need to be aware of the role they play in ensuring that the learners are given the right amount of encouragement and types of questions which nurtures the development of the voice (Harter et al., 1997).

The integration and emphasis of critical thinking in the current education system demonstrates a constructive growth in curriculum development and learning outcomes. By developing a more student-centered approach in their learning environment, young learners themselves have discovered a whole new surrounding in terms of their comprehension and evaluation of knowledge. This 
paradigm shift in education reveals a growing need to raise a whole generation of critical minded citizens who are able to rise up to the challenges of globalization where without the ability to think critically one would be greatly challenged in the face of a whole host of complex tasks and roles. The involvement of critical thinking in all elements of study emphasizes a signifying leap towards producing a more thinking and critical-minded society. The thinking abilities of a society then indicates a more developed and positive future nation of young leaders. Hence, it is asserted that the learning outcomes in education reflect the centering of critical thinking skills among others as an essential element towards producing more engaged and empowered generation.

Developing critical mindedness among young learners requires critical thinking to be delivered via the exposure to the polymorphous and multifaceted nature of critical thinking manifested in the different domains that learners could develop their critical thinking faculties more holistically. By this exposure, young learners awareness of the different manifestations of critical thinking in their varied range of subjects is increased. With regard to this, the other vital goals of education are not to be forgotten but to be integrated with the element of critical thinking which then facilitates impressive formations of young learners self awareness and management.

The hypothesis is young adult learners are at a stage of life where they are developing interests in private and public matters. In order for them to be better empowered in their own learning process they require a few givens. Firstly, it is essential for these learners to have their minds engaged/interested in the topic at hand. Second, it is also equally vital for these learners to possess a mind that is critically aware of their own surroundings. These two components together help facilitate the young learners towards empowerment in their learning environment. How is the students sense of self presented in the learning environment? Are they encouraged or discouraged to develop a voice? Are certain voices given more emphasis then others? These issues are foregrounded in the study as we attempt to gauge the young adults responses to the issue of critical thinking.

\section{MATERIALS AND METHODS}

The respondents are young adult learners of two very diverse backgrounds and subject areas. The first is a group of 1st year undergraduate students from University Kebangsaan Malaysia who are majoring in Literature in English Program and currently undertaking a course on Critical Appreciation. This sample group ranges between 19-21 years of age. These respondents are made up solely of Malaysians. The second group is also made up of 1st year undergraduates from Segi University College who are majoring in Business Management
Program and who are currently undergoing a Core Business Skills course. This group aged between 19-25 years of age. These respondents comprised of those from Malaysia, China, Africa and Middle Eastern countries. Both of these diverse sample groups comprised of a healthy gender proportion. The rationale behind the researchers choice of these respondents is that young adult learners in institutions of higher learning require essential skills to enable them to adapt in the face of change and become more aware and receptive for the need to make complex decisions swiftly, act ethically, respect the ideas of others (Bowers, 2006).

In order to ascertain what engages the young adult learners in the respective institutions, we formulated a set of questions to solicit their reading, listening and viewing responses as well as to better understand their point of view vis-"-vis the issues of critical thinking. The questions were formulated along three trajectories: the first is on the importance of self interests in the selection of reading/listening/viewing materials and in the choice of topics and themes discussed. The second is on the importance of self perception regarding the topic of critical thinking and the third is the importance of learner response in approaching any text. Questionnaires utilizing multiple-choice questions are administered to gauge and obtain qualitative as well as quantitative information. Hence, it is the hypothesis that the three trajectories along with the two case studies will assist us to form a clearer understanding of the learners perspectives which will then facilitate us to create a more engaging learner centered teaching-learning environment for the students.

\section{RESULTS AND DISCUSSION}

The data collected is tabulated according to the three trajectories set at the onset of the study-self interest, self perception and self response. This study presents the analysis of each theme separately using the data collected.

Self interest: This study of the questionnaire attempts to identify the types of topics, themes and materials that engage the young adult learners from both institutions. Generally, both samples appear to show interest in the similar reading, listening, viewing materials. As shown in the figures below, popular texts and material connected to the media appear prominent choices amongst the students from both institutions with movies getting over $12 \%$ of each class preference. Literary reading materials such as novels, poems, short stories on the other hand, appear to be less interesting to these students albeit the UKM sample shows a higher percentage. As the students are majoring in Literature in English this finding is rather expected (Fig. 1 and 2). Another significant similarity 
between the two samples can be seen in the choices of topic as shown in the two figures below. Albeit both samples emphasized differing themes, a significant pattern appears to materialize in the choices made. Relationship appears the most prominent topic for both samples with over $13 \%$ for each sample and this is followed by other relational type topics such as friendship group, family, society, responsibility and culture. In addition, topics connected to the self such as self identity and physical appearance are also prominent in both samples.

However, the most significant difference between the topic samples vis-a-vis the topic choice can be seen on the topic of career. Unlike the UKM sample who as stated earlier is made up of young adults from Malaysia who are undertaking the Critical Appreciation course, the Segi College sample learners who are studying Core Business Skills appear to place more emphasis on career as a topic that engages them Fig. 3 and 4. The learners were also questioned on their choice of themes and the findings further illustrate the importance placed on relational issues. As the data shows, the three themes that received the most votes are similar for both groups. These themes include issue of trust in relationship, over $15 \%$ for both groups followed by developing positive self image (over 13\% for both groups). Incidentally, both themes

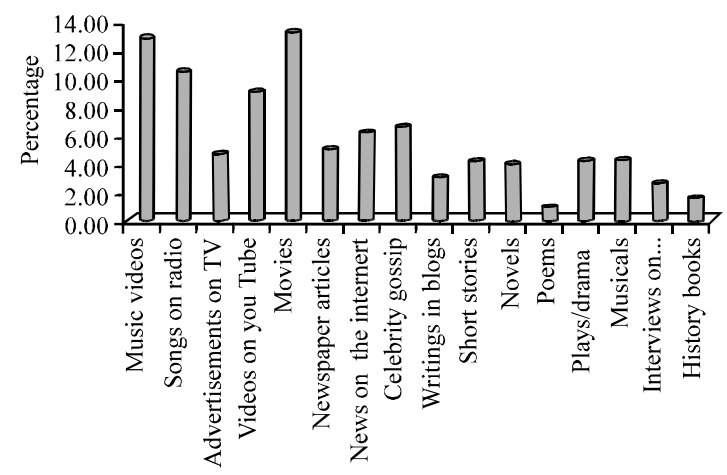

Fig. 1: Segi college and choice of material

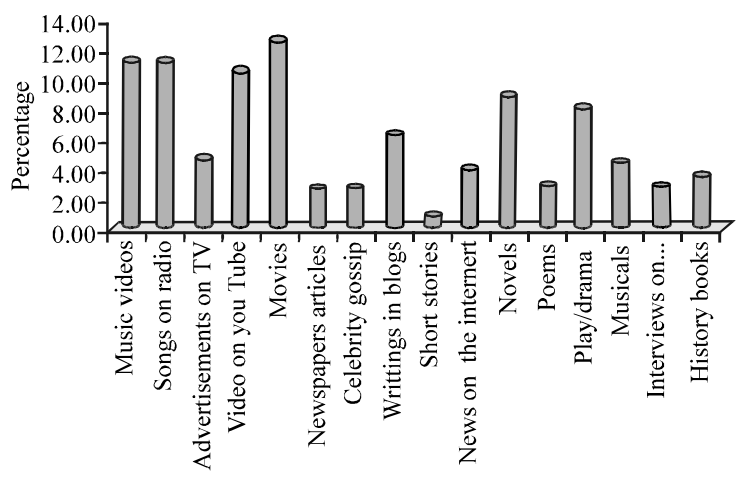

Fig. 2: UKM and choice of material appear as prominent topics for both groups as earlier analyzed. And the theme least voted for as a preference is developing patriotism (Fig. 5 and 6).

Self perception: The second section of the questionnaire attempts to identify the young adult learners perception about the issue of critical thinking and its availability in their learning environment. Majority of the young learners from both samples (over 44\%) agree that having an opinion about the things they read/view/listened to denotes critical thinking. Even though these learners perceive that all the four components-to evaluate to question, to have an opinion and to construct arguments are the parameters of critical thinking, emphasis appears to be placed on having an opinion.

When asked about whether critical thinking important to their learning, both groups are in tandem in their answer with almost $95 \%$ seeing its importance. However, when asked whether their current learning environment presents opportunities for them to question, evaluate and argue about different issues the two groups begin to show significant differences.

With UKM sample, almost $80 \%$ say that they are given the opportunity to do so. Whereas with the Segi sample, barely $25 \%$ feel like they are able to do so. When questioned why this is as such a very significant percentage, nearly $40 \%$ appear to perceive that their opinions might be wrong or unaccepted. Equally

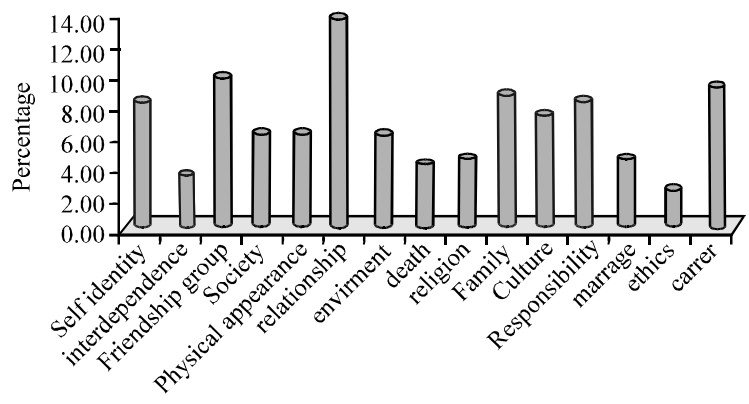

Fig. 3: Segi college and choice of topics

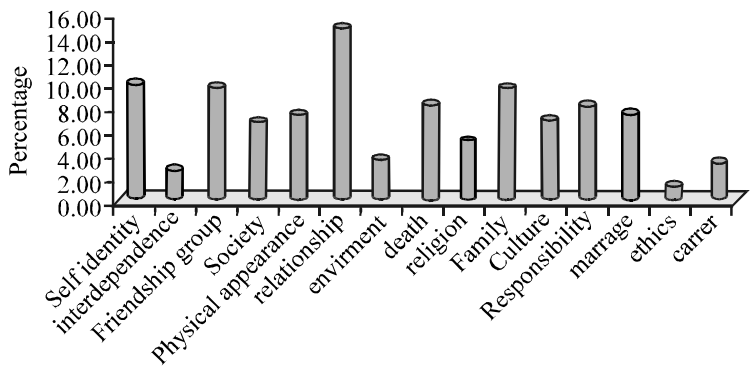

Fig. 4: UKM and choice of topic 


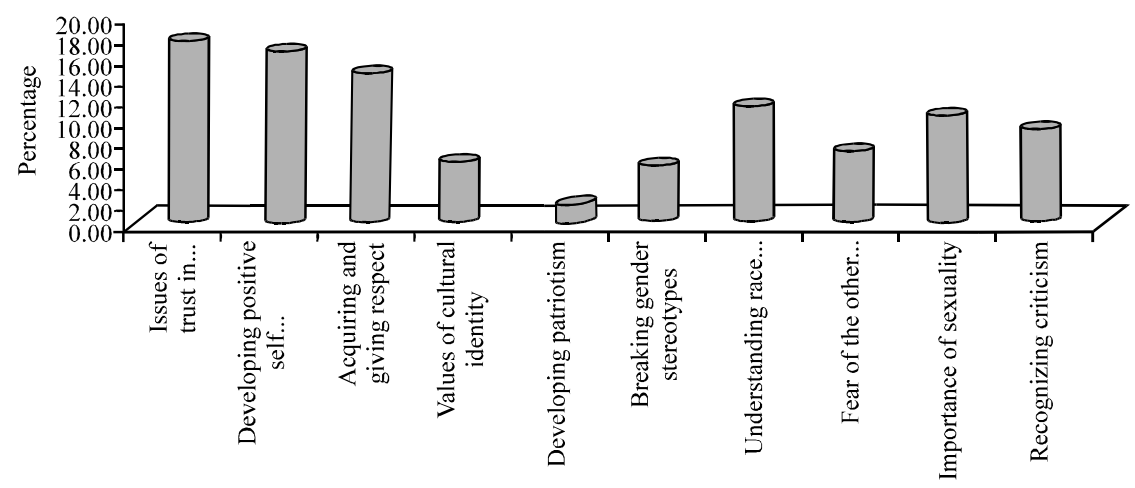

Fig. 5: Segi college and choice of theme

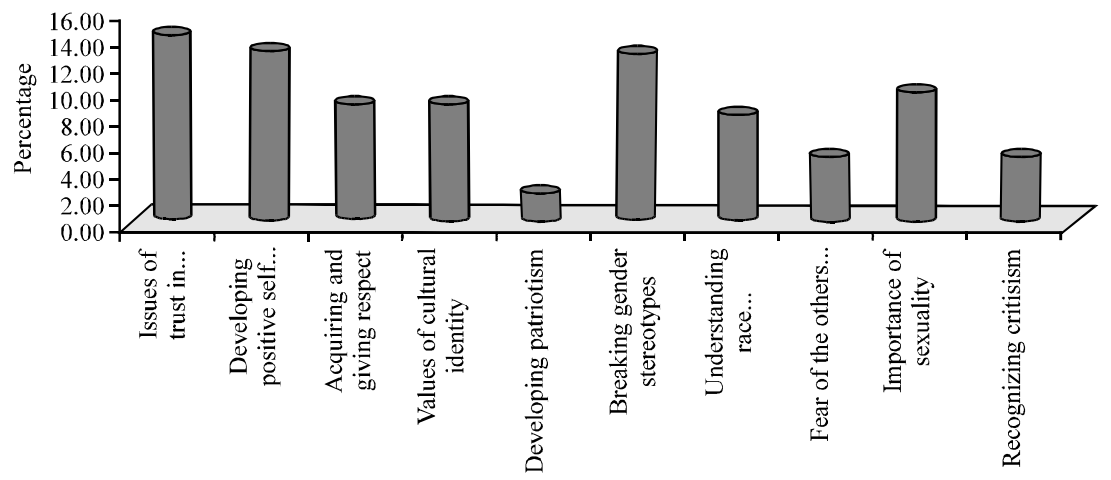

Fig. 6: UKM and choice of theme

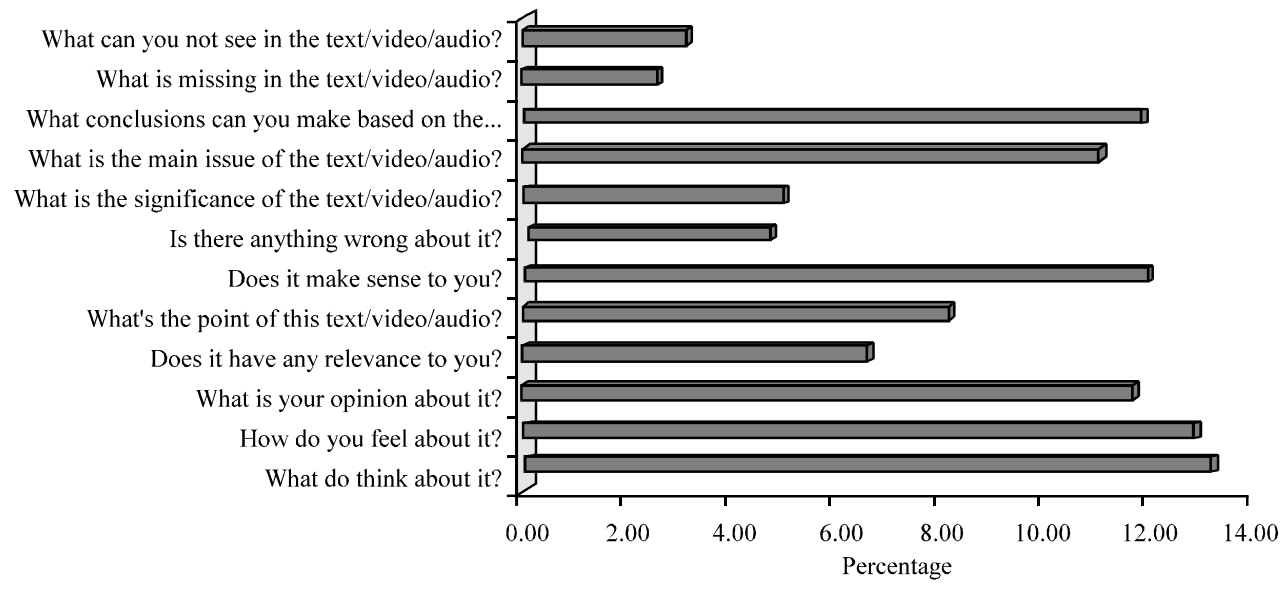

Fig. 7: Segi college and types of questions asked

significant is that over $10 \%$ feel that they are not interested to do so and over 5\% feel that their subject matter is too theoretical.

The final question which engages the learners perception on the topic of critical thinking focuses on the types of questions students like to answer when reading text, watching film or listening to an audio. Generally, both groups are receptive towards most types of questioning which involves the thinking process or the emotional connection or the relevance of their context, i.e., aspects of both the cognitive and affective, appear significant. However, the Segi sample appears more prone to questions in sync with their emotions (Fig. 7 and 8). 


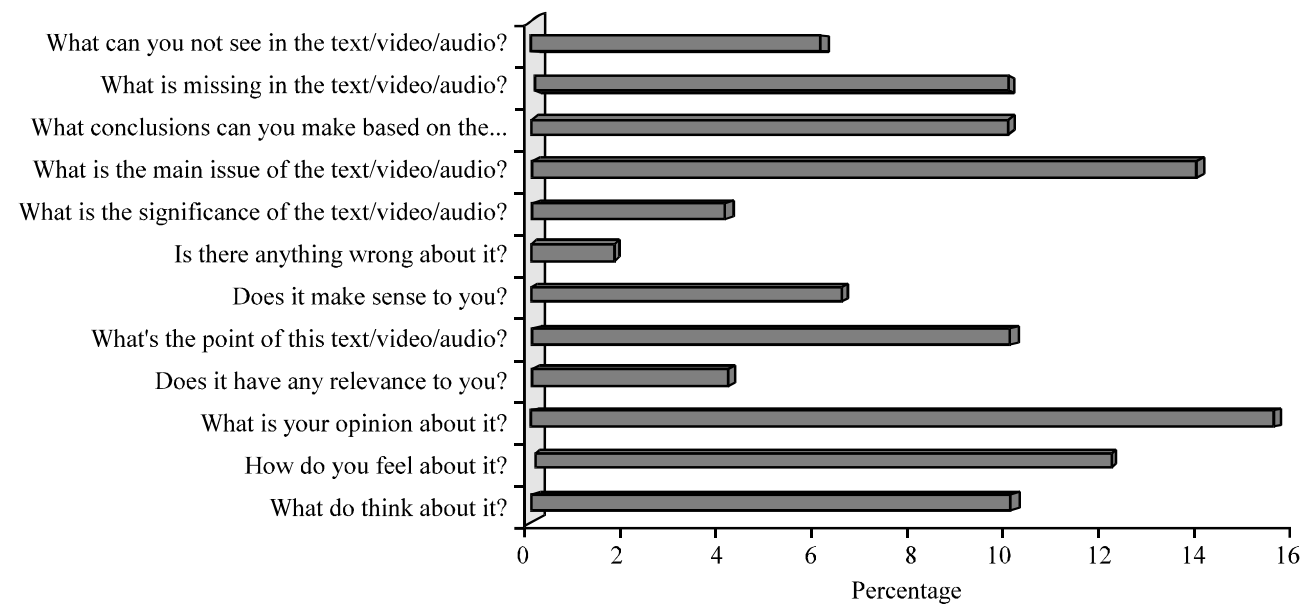

Fig. 8: UKM and types of questions asked

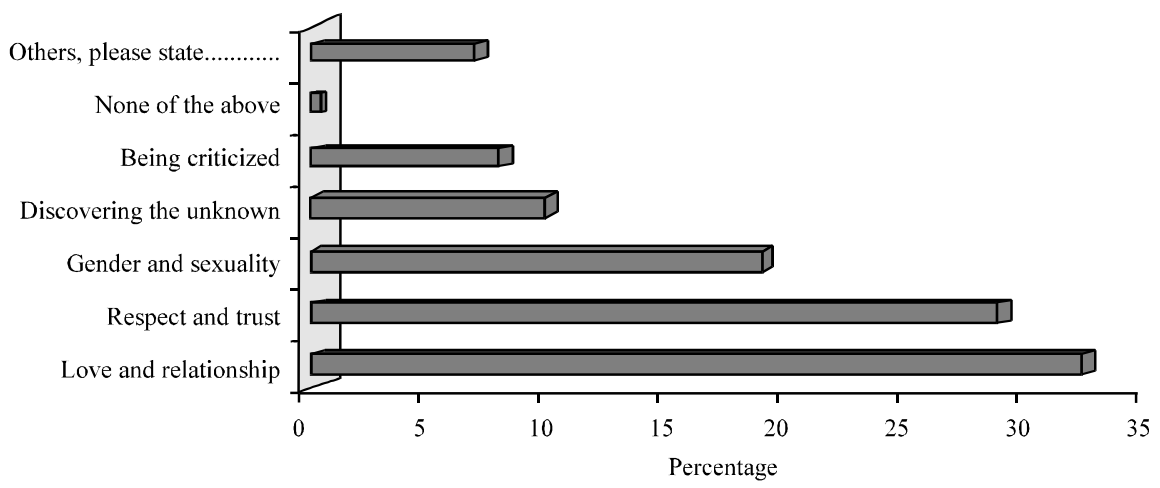

Fig. 9: Segi college and text 1

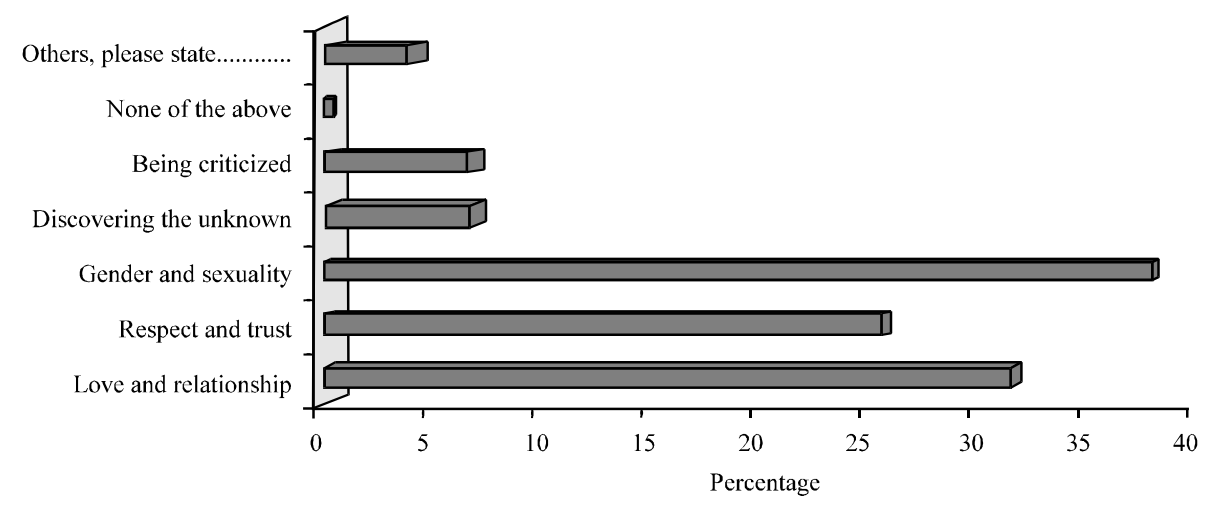

Fig. 10: UKM and text 1

Self response: The third and final section of the questionnaire attempts to solicit the learners responses to the different reading materials provided. There were four materials and each is from a different genre. The first is a popular song, the second is a popular cartoon strip, the third is a poem from the American literary canon and the fourth is an advertisement. Each text presents an opportunity for the learners to respond in a critical and creative manner. The first text that the learners are given is a popular song sung by beyonce and written by Toby $\mathrm{Gad}$ and BC Jean. The learners were given a list of possible themes to choose which includes-love and relationship, respect and trust, gender and sexuality, discovering the unknown, being criticized, None of the 

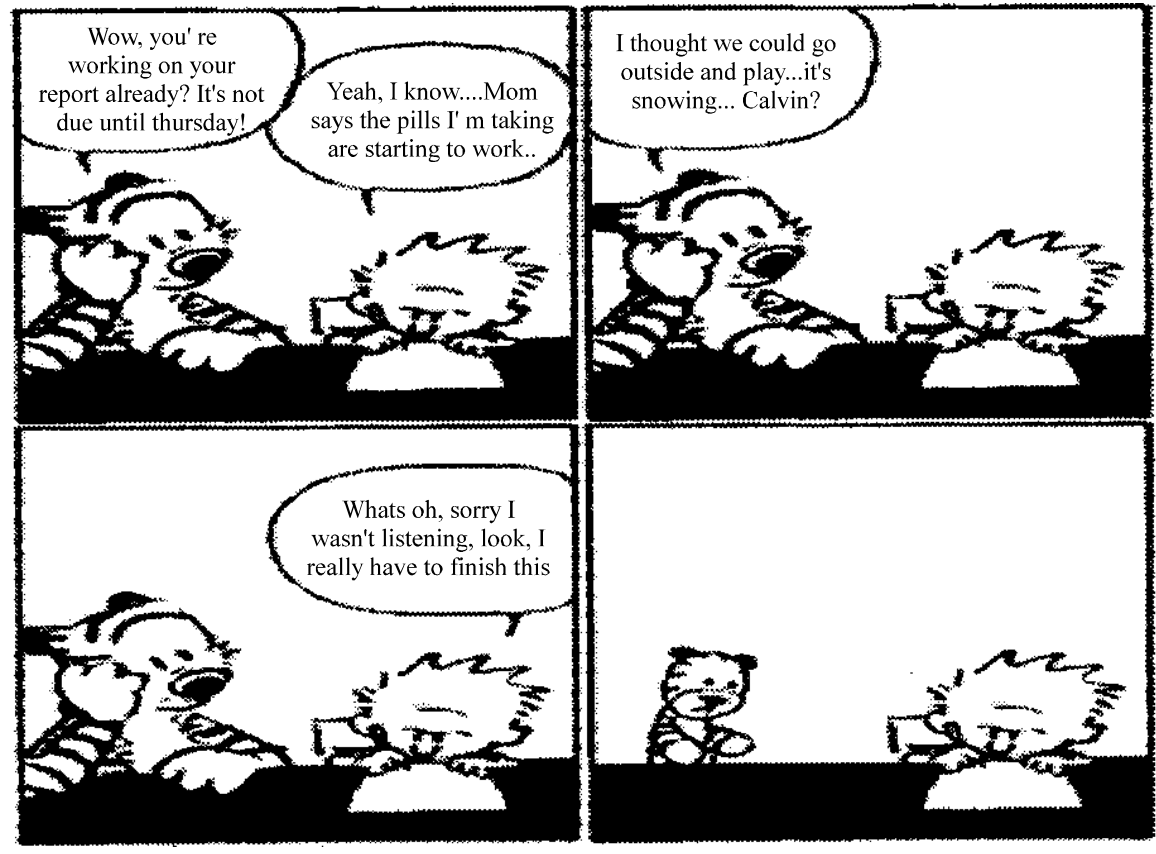

2. What is the main issue in the cartoon strip?

- Loss of innocence

- Being a good student

- Death of the creative mind

- Being a good son

- The importance of the

rational mind

- None of the above

- Others

Please state.

Calvin and Hobbs

Fig. 11: From Calvin and Hobbs

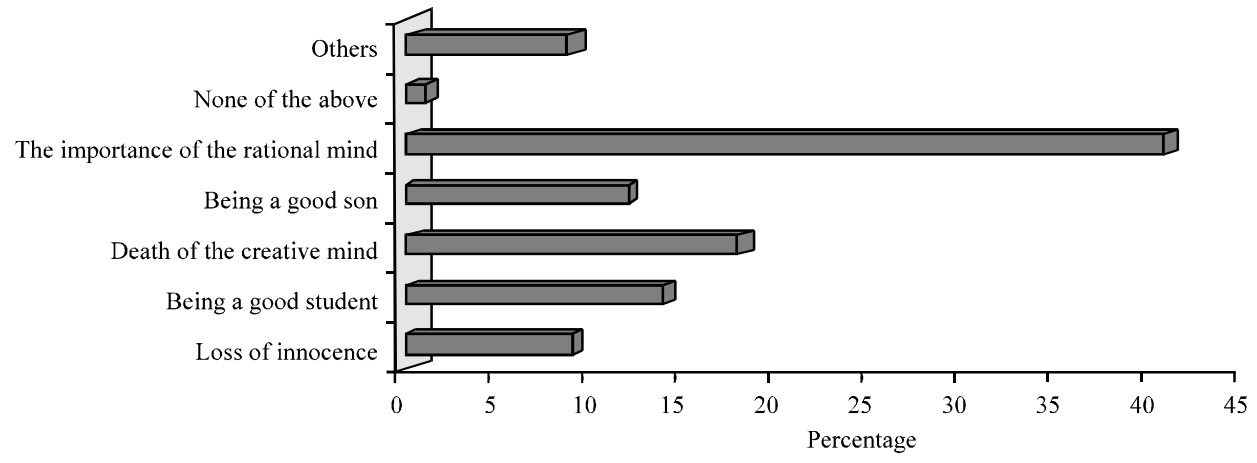

Fig. 12: SegiCollege and text 2

above, others. Generally the responses to the text highlight that both groups appear to pick up on interests that were highlighted in the beginning.

For instance, the UKM sample appears to place a higher percentage on the themeof gender and sexuality on the 1st text whereas the Segi sample appears to place a higher percentage on love and relationship. However, this finding is not conclusive and requires further investigation in order to ascertain its validity (Fig. 9 and 10).

On the other hand, for the second texts, the responses were move varied. The text seeks to gauge the students' respond on the situation in which the young child has to choose between his rational mind and his imaginary playmate. The choice will have apparent consequences as shown in the comic strip (Fig. 11).

Calvin and Hobbs: The findings suggest that almost all the learners are able to respond to the text in a positive manner by picking on the appropriate possible theme. However, the level of respond varies. The options given attempts to create a range of possible reading from the more conception type answer i.e., being a good son and being a good student to a more inference based answer, i.e., death of the creative mind and loss of innocence (Fig. 12 and 13). 
Res. J. Applied Sci., 5 (6): 471-479, 2010

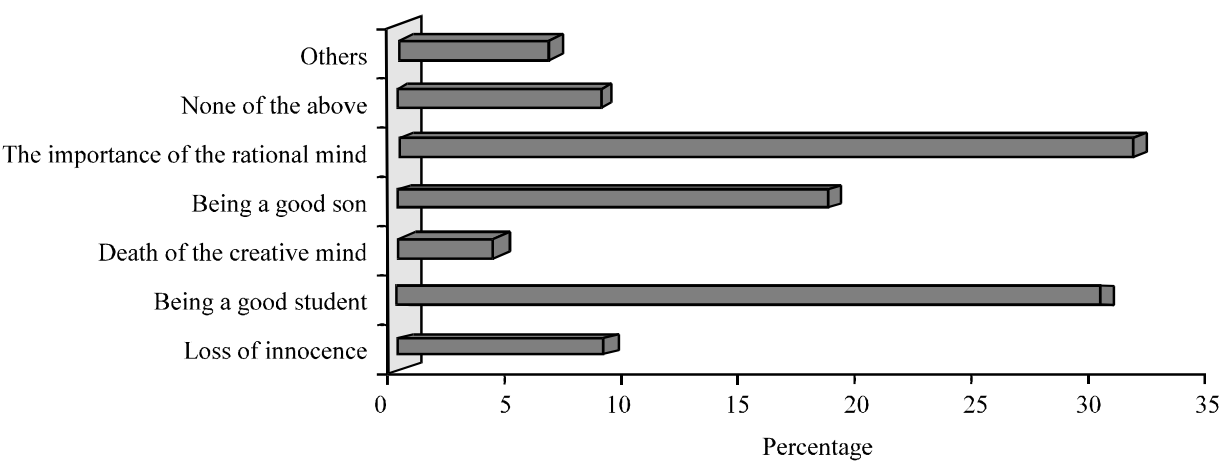

Fig. 13: UKM and text 2

\section{CONCLUSION}

This study set out to discover the voice and mind of the young adult learners in two different institutions in Malaysia in order to facilitate the educationists with the necessary information that can create a more learner centered teaching environment. Using a public and private institutions of higher learning in Selangor, the research set out to gauge the level of critical mindedness available in the undergraduate students. Based on the discussion above, certain important conclusions can be drawn out.

To begin with both groups of students value the importance of interpersonal relationships as seen in their choice of topics, i.e., relationships, friendship and family as well as choice of themes i.e., issues of trust in relationships and acquiring and giving respect. However, the interpersonal relationship appears to be confined to a more face to face and immediate surrounding as opposed to being connected to the imagined community. This is to be expected as the group comprises of young adult learners who are preoccupied with the immediate and not so much the future.

In addition, the difference in selected students choice of discipline also appears to colour their mind. In terms of their response to whether or not critical thinking is appreciated, the difference between the two groups becomes obvious vis-a-vis subject matter. Segi sample which constitute students who are majoring in business management perceive their theoretical nature of their syllabus hinders the critical thinking process in their learning environment. Unsurprisingly then the UKM sample which constitutes students studying Critical Appreciation are not hindered by their subject albeit they are hindered by their self-confidence with over $20 \%$ choosing inabilities or wrong or unaccepted opinions as the reasons why critical thinking is not available in their learning environment. Furthermore, using the three trajectories of self interest, self perception and self response, the preliminary data shows that the young adult learners from both samples do engage with the issues presented. In fact it can be concluded that they do form opinions about the texts presented to them and the issues asked of them. It would not be fair to assume that these learners are without an opinion or lack the ability to think. However, the level of critical mindedness are not easily ascertain given the current data. A more indebt investigation into the student's approach to the respective subject is necessary to form any sound conclusion on this matter.

It is unquestionable that critical and an empowered mind will enable the young adult learners to not just be successful in securing a university qualification, more importantly it will secure them a purpose and direction in their life. To quote Ronald Barnett (Batchelor, 2008): It is not knowledge that will carry them (graduates) forward but their capacity to embrace multiple and conflicting frameworks and to offer their own positive interventions in that milieu. What counts is not their knowledge but their mode of being.

It is the mode of being that educators need to emphasize in tandem with the curriculum of the respective courses. What can be concluded based on these preliminary findings of the two case studies of young adult learners is that albeit available, critical thinking is still a skill that requires nurturing on the part of the educators. Confidence in one's opinion is still a pressing concern among many of these learners and until that issue is dealt with the development of critical mind in these learners might not reach the level that each one is capable of.

\section{REFERENCES}

Barnett, R. and R. di Napolli, 2008. Changing Identities in Higher Education: Voicing Perspectives. Routledge, London. 
Batchelor, D., 2008. Have Students Got a Voice. In: Changing Identities in Higher Education: Voicing Perspectives, Barnett, R. and R. di Napoli (Eds.). Routledge, London, pp: 40-54.

Bowers, N., 2006. Instructional support for the teaching of critical thinking: Looking beyond the red brick wall. Crit. Think., 1: 10-25.

Cleary, B.A., 1995. Empowerment in the learning process: A framework of theory, process and tools. Empowerment Org. Int. J., 3: 6-9.

Cowley, B.J., A. Lindgren and D. Langdon, 2006. Using self-experimentation and single-subject methodology to promote critical thinking. Crit. Think., 1: 26-30.

Harter, S., P.L. Watera and N.R. Whitsell, 1997. Lack of voice as manifestations of false self behavior among adolescents: The school setting as a stage upon which the drama of authenticity is enacted. Educ. Psychol., 322: 153-175.
Locke, D.C., 1992. Increasing Multicultural Understanding: A Comprehensive Model. Sage Publications, London.

Mezeske, B., 2004. Shifting paradigms: Don't forget to tell your students. Teach. Professor, 18: 1-1.

Rudinow, J. and V. Barry, 2008. Invitation to Critical Thinking. Wadsworth Publishing, Australia.

Too, W.K., 2006. Young adult literature: An alternative genre in classroom reading list. English Teacher, 28: 41-59.

Vethamani, M.E. and T.W. Keong, 2008. Connecting linking park and good charlotte to ESL learners. $3 \mathrm{~L}$ Language Linguistics Literature, 14: 95-108.

Weimer, M., 2002. Learner-Centered Teaching: Five Key Changes to Practice. 1st Edn., Jossey-Bass, San Francisco, pp: 288.

Wohlfarth, D.D., D. Sheras, J.L. Bennet, B. Simon, J.H. Pimentel and L.E. Gabel, 2008. Student perceptions of learner-centered teaching. InSight $\mathrm{J}$. Scholarly Teach., 3: 67-74. 